\title{
CIÊNCIA E SOCIEDADE: A EDUCAÇÃO EM TEMPOS DE FRONTEIRAS PARADIGMÁTICAS
}

\author{
SCIENCE AND SOCIETY: EDUCATION IN TIMES \\ OF PARADIGMATIC FRONTIERS \\ SCIENCE ET SOCIÉTÉ: L'ÉDUCATION À L'ÉPOQUE \\ DES FRONTIËRES PARADIGMATIQUES \\ CIENCIA Y SOCIEDAD: LA EDUCACIÓN EN TIEMPOS \\ DE FRONTERAS PARADIGMÁTICAS
}

Lais Maria Borges de Mourão Sá*

\begin{abstract}
RESUMO
Este artigo faz uma ponte entre as idéias de Boaventura de Sousa Santos, a respeito do papel da universidade pública na construção de um projeto de sociedade contra-hegemônico à globalização capitalista, e as idéias de István Mészáros, a respeito da radicalidade de uma educação para além do capital. Na costura dessas duas visões da mudança social, utilizamos a visão de Edgar Morin sobre a natureza complexa dos paradigmas e as condiçöes socioculturais de sua transformação. Indagam-se aqui as possibilidades de produção de um novo conhecimento enraizado nas lutas sociais pela superação da hegemonia da lógica do capital e de sua determinação sobre a produção material, cultural e educacional de nossa sociedade. A universidade pública é considerada como espaço privilegiado de democratização da produção do saber científico e de contribuição à construção de um projeto de sociedade revolucionário.
\end{abstract}

Palavras-chave: Universidade pública. Mudança de paradigmas. Saber científico.

* Doutora em Antropologia Social pela Universidade de Brasília (UnB, 1992). Pós-Doutora em Educação Ambiental pela Universidade Estadual de Campinas (1999). Docente da Faculdade de Educação e do Centro de Desenvolvimento Sustentável da UnB (lais.maria@terra.com.br). 


\section{EDUCAÇÃO E MUNDO DA VIDA}

No contexto do capitalismo globalizado contemporâneo, a instituição universitária vem perdendo legitimidade como locus de produção de um conhecimento científico crítico, capaz de contribuir na proposta de alternativas de transformação social.

Refletindo sobre os efeitos desta conjuntura histórica, Boaventura de Sousa Santos (1989a, 1989b, 2005) destaca o abandono, por parte da instituição universitária, de sua tarefa de reflexão crítica sobre o projeto de sociedade no longo prazo. $\mathrm{O}$ fato de a ciência ter se tornado uma força produtiva a serviço dos interesses do capital fez com que a universidade perdesse a autonomia quanto às intençōes, métodos e temas de pesquisa. Um progressivo processo de privatização vem ocorrendo no interior das relações institucionais, postergando as prioridades coletivas e colocando a produção do conhecimento científico a serviço de interesses particularistas.

De um lado, a pressão privatista da indústria capitalista pela produção de um conhecimento-mercadoria. De outro, a responsabilidade social da universidade pública, no sentido de responder às demandas sociais pela construção de uma ciência democrática e transformadora.

Santos (2005) observa que essa perda da capacidade reflexiva e crítica da universidade pública na formulação de um projeto nacional se deve à própria natureza da dominação política neo-liberal do sistema do capital globalizado, ao qual não interessa a construção de projetos que reforcem a autonomia dos espaços nacionais. E conclui: sem projeto nacional autônomo não há universidade pública, ao mesmo tempo em que não pode haver autonomia nacional sem a definição de estratégias contra-hegemônicas globais ao sistema do capital globalizado.

Dessa forma, a transformação revolucionária da universidade implica retomar a sua participação na construção de um novo projeto de sociedade, qualificando essa construção na dimensão global em que hoje está posta a disputa por uma nova ordem mundial.

Para Santos (2005), trata-se de um projeto que tenha como base valores de reciprocidade e bem comum, capaz de propor uma nova transnacionalização alternativa e solidária. No plano da educação, um projeto dessa natureza integra e potencializa os novos processos de produção e difusão de conhecimento e as novas pedagogias emergentes da experiência social de luta por um novo projeto de sociedade.

Coloca-se, assim, a necessidade de articular a questão da emancipação da universidade pública a uma visão mais abrangente da educação, capaz de romper com os enquadramentos institucionais que a viabilizam enquanto instrumento formal de reprodução social do sistema do capital.

No sentido antropológico, educação é o processo social pelo qual uma geração transmite à outra a visão de mundo que define a sua identidade coletiva. Nas sociedades complexas e hierarquizadas, cujo controle social é centralizado pelo Estado, a educação se cristaliza em formas institucionais que operam como instrumentos da formatação ideológica dos indivíduos sociais dentro dos princípios do paradigma dominante. 
Mészáros (2002 e 2005) utiliza a noção de "indivíduo social" para designar a coexistência entre singularidade pessoal e identidade social, ou vínculo grupal e de classe. Seja qual for o modo de produção social, é certo que a educação formal tem sempre como meta fazer com que cada indivíduo se torne e permaneça social, ou seja, incorpore na reprodução de sua vida pessoal os modos de existência social dominantes, seja no sentido da replicação, seja no sentido da transformação dos padrōes sociais vigentes.

Porém, a formação da pessoa no mundo da vida inclui outros vínculos muito mais profundos do que o das relações institucionais, e, apesar da dominância da educação formal, os espaços de recriação intersubjetiva permanecem mais ou menos livres, a depender da relação entre autonomia e dependência permitida pelos controles centrais a que estão submetidos os indivíduos sociais.

Nunca é demais salientar a importância estratégica da concepção mais ampla de educação, expressa na frase: 'a aprendizagem é a nossa própria vida'. Pois muito do nosso processo contínuo de aprendizagem se situa, felizmente, fora das instituiçôes educacionais formais; (...) esses processos não podem ser manipulados e controlados de imediato pela estrutura educacional formal legalmente salvaguardada e sancionada (MÉSZÁROS, 2005, p. 53).

No sistema do capital, segundo Mészáros (2005), a separação entre o capital e o trabalho faz com que a educação formal seja um instrumento pelo qual se opera efetivamente a subordinação das necessidades sociais às necessidades de reprodução do capital e o enquadramento do indivíduo social às determinaçôes do mercado de trabalho. Indagando sobre o impacto da lógica do capitalismo na educação, o autor constata que a consciência é modelada pela educação institucionalizada no interesse do controle do capital sobre o trabalho, gerando e transmitindo um quadro de valores que legitima esse interesse dominante. Mészáros chama de 'internalização' o processo educativo pelo qual os indivíduos são induzidos, de acordo com sua posição na ordem social, e com as tarefas reprodutivas que lhes forem atribuídas, a uma aceitação ativa ou resignada dos princípios dominantes da sociedade.

Verifica-se, então, a necessidade de desenvolver o conceito de paradigma para esclarecer o modo pelo qual se dá essa internalização dos princípios da ordem social na formação coletiva dos indivíduos sujeitos, dentro ou fora dos espaços institucionais, e também para que se possa identificar as condições de sua transformação.

Refletindo sobre a natureza dos paradigmas na cultura humana, Edgar Morin (1992) identifica-os enquanto núcleos de pensamento organizadores da sociedade, relações lógicas que se inscrevem culturalmente nos indivíduos. Morin vê nos paradigmas um sentido ao mesmo tempo generativo e organizacional, nos níveis semântico, lógico e ideológico. Assim, o paradigma é o que promove e seleciona as categorias mestras da inteligibilidade, prescreve a utilização cognitiva, valida e universaliza a lógica que elege; dá qualidade de verdade e necessidade às categorias e discursos que controla; funda o axioma e se expressa nele.

O paradigma atua como um vírus: é um programa no espírito de cada sujeito, e pensa por meio dele. Inconsciente e sobreconsciente, controla o pensamento 
consciente, organiza a organização do mundo cultural. É no processo educativo que os princípios paradigmáticos se internalizam como profundas e inconscientes raízes na subjetividade individual e coletiva. Daí a sua grande resistência a qualquer intenção consciente de mudança.

Porém, a racionalidade dos paradigmas também se desgasta internamente, pela possibilidade, nunca totalmente eliminada, de brechas e espaços de autonomia que escapam ao controle dominante, presença da desordem que permite a emergência de novas significaçôes de dentro do movimento da ordem estabelecida. No processo contínuo de aprendizagem que é a dinâmica organizativa de todo sistema vivo, as possibilidades de recriação autônoma dos indivíduos sociais não cessam de engendrar suas sementes de transformação.

Assim, em algum momento crítico dos processos históricos, as revoluções paradigmáticas se manifestam como novas emergências, a partir de mudanças nos núcleos organizadores do sentido que contaminam o universo cultural, recriando de dentro para fora a visão de mundo e o projeto de sociedade. Trata-se de uma transformação do modo de pensamento, do mundo do pensamento e do mundo pensado, cujo exemplo mais clássico, no ocidente, é a revolução copernicana.

Apesar do enraizamento profundo dos paradigmas na realidade sociocultural e psíquica, chega sempre o momento em que emergem as condiçôes inerentes de sua transformação, devido à própria natureza complexa e dinâmica dos conflitos e contradições socioculturais. Fraturas e contradições na organização da sociedade geram conjunturas históricas favoráveis à emergência de uma concepção alternativa de mundo. Esses são os momentos da ação política consciente e da articulação entre todas as forças interessadas em um novo projeto de sociedade.

\section{EDUCAÇÃO E MUDANÇA DE PARADIGMAS}

Porém, os paradigmas manifestam uma grande força de resistência às investidas meramente reformistas. Mészáros (2005) é taxativo: reformas são corretivos marginais que não eliminam os fundamentos causais da totalidade sistêmica reguladora do capital.

Todo reformismo pensa e propõe mudanças superficiais, que, na verdade, só atuam sobre aspectos particulares, sem abordar as contradições do sistema do capital. Com isso, desviam a atenção das determinações sistêmicas e da causalidade estrutural, enfraquecendo as forças sociais que desejam construir um sistema alternativo. As propostas reformistas desconhecem ou eludem uma verdadeira compreensão sobre o modo de organização e atuação dos paradigmas na construção da ordem social.

Morin (1992) compara as tentativas reformistas de mudança social com a tentativa de remendar um pote de barro rachado: não é possível acumular a água, ela continua se perdendo, e por maior que seja a habilidade do artesão, ou a quantidade colocada dentro do pote, a água sempre escapará por entre as rachaduras. Ações reformistas produzem efeitos paliativos de curto alcance, pela ausência de uma compreensão mais radical (que atinja a raiz) sobre a verdadeira natureza dos 
fenômenos que pretendem transformar. Perguntas essenciais ficam ocultas, e esse ocultamento é responsável pelo efeito oposto ao esperado. A habilidade de fazer as perguntas corretas é o que permite desvelar a verdadeira natureza dos paradigmas, para que possam ser transformados de modo eficaz, isto é, revolucionário.

Nas tentativas reformistas da educação, há sempre algo subjacente que permanece intocável: o modelo de sociedade que define as prioridades para a pesquisa científica, para a lógica empresarial, para o mercado de trabalho e de produtos, as relaçôes de inserção no mercado globalizado. Esse modelo implica em algumas escolhas e premissas que foram antecipadamente aceitas e que definiram um padrão para as políticas e projetos, organizando a forma com que se pensam as categorias explícitas das propostas.

Isso que está sustentando ocultamente as propostas é imperceptível aos sujeitos sociais, pois os sistemas de idéias, ou paradigmas, não são construção de uma pessoa, nem mesmo de um grupo que controla o Estado. Eles são fruto de processos históricos suficientemente antigos para criar um elo profundo entre a força das idéias e dos modos de organização das relações sociais e as ações do presente, estas, sim, de indivíduos concretos que agem sem questionar os padróes e valores herdados, quer por interesse, por inércia, ou ignorância da verdadeira natureza dos paradigmas na sociedade humana.

Assim como o projeto de uma nova educação não irá se impor simplesmente pela vontade de alguns indivíduos e grupos, também a superação do modelo atual não cessará de reproduzir seus efeitos de exclusão social e degradação ambiental, enquanto não se explicitarem e não forem diretamente atacados com ações concretas os princípios ocultos que organizam as suas regras e categorias. Princípios que atuam, inconscientemente ou não, em nossas intenções, reduzindo ao já conhecido as possibilidades de novas criações, mudando os rótulos sem substituir os conteúdos internos das idéias e ações.

No caso das propostas de reforma das instituições formais de educação, não se pode esquecer que elas reproduzem internamente as relaçôes que sustentam o paradigma do capital. Portanto, o caminho para romper com essa lógica não pode ser o de uma reforma institucional formal, mas deve partir de uma compreensão lúcida e crítica sobre as condiçôes históricas do momento e de uma proposta revolucionária, capaz de transformar o modo pelo qual os princípios essenciais do paradigma dominante se manifestam no quadro institucional da educação.

Morin (1992) demonstra que, devido ao enraizamento profundo dos paradigmas na realidade socio-cultural, noológica e psíquica, a transição paradigmática se dá no nível arquetípico dos códigos culturais e sociais. Ela significa uma mudança nos núcleos organizadores das relações entre os indivíduos sociais. Para ele, as précondições para o período de transição são as crises interdependentes, que emergem em condições históricas, sociais e culturais sem comando central consciente, momentos em que ocorrem fraturas na organização da sociedade e do pensamento.

Nesse sentido, existem freqüentes oportunidades oferecidas pelas crises estruturais cíclicas do sistema do capital, resultantes de sua dinâmica de constante expansão e acumulação pela ampliação de escala. Essas crises se constituem em importantes 
momentos de aguçamento do antagonismo básico entre capital e trabalho e oferecem seguidamente possibilidades de transição que podem ser desenvolvidas politicamente no sentido da consolidação progressiva de uma nova lógica de organização social.

Mészáros (2005) sublinha que é no nível político-social que deve ser construída a transição político-pedagógica necessária para essas profundas transformações, pelo desenvolvimento dos potenciais crítico-libertadores capazes de gerar autonomia e proposição de modos alternativos de organização sociopolítica do mundo do trabalho. Uma atividade de contra-internalização coerente que não se esgote na mera negação do sistema do capital, mas que atue nos espaços e tempos das crises estruturais com alternativas abrangentes e concretamente sustentáveis.

Trata-se, assim, de romper o círculo vicioso do controle social do capital e a dependência negativa e defensiva em relação a ele, por meio da reestruturação dos poderes de tomada de decisão, nos diversos espaços sociais e institucionais onde essas novas experiências se implantam.

No âmbito da educação formal, e da universidade em particular, essas possibilidades apontam para a necessidade de transformar o modo de internalização das regras de reprodução do sistema do capital por dentro da vida acadêmica, desmontando as limitações impostas pelo mercado de trabalho à formação profissional, e o atrelamento da pesquisa técnico-científica aos interesses do capital.

$\mathrm{Na}$ transição da educação organizada pelo sistema do capital para uma educação que promova a plenitude da vida humana, é preciso uma transformação emancipadora do trabalho. Uma proposta institucional enraizada na vida, um processo de educação que cultive as raízes de um novo modo de reprodução social do trabalho e que, ao influenciar as tendências culturais, atinja simultaneamente, e por isso mesmo, os modos de reprodução social do paradigma do capital.

\section{TRABALHO E EDUCAÇÃO}

Considerando o trabalho como a atividade criadora humana e a educação como o processo de desenvolvimento permanente dessa capacidade, é preciso que a educação esteja a serviço da auto-realização dos indivíduos e não da ordem alienante do capital. Mészáros (2005) repõe, em sua reflexão sobre a educação para além do capital, a proposição marxista de que a auto-alienação do trabalho está na raiz de todas as formas de alienação.

Apenas a mais ampla das concepçôes de educação nos pode ajudar a perseguir o objetivo de uma mudança verdadeiramente radical, proporcionando instrumentos de pressão que rompam a lógica mistificadora do capital (MÉSZÁROS, 2005, p. 48).

Para o autor, colocar como meta do processo educativo a superação da autoalienação do trabalho significa formar pessoas capazes de realizar o processo de transição social para o paradigma da igualdade substancial dos indivíduos sociais e sua livre associação no controle consciente do processo de reprodução social. Nessa 
transição são criadas formas alternativas às relações alienadas de mediação do sistema do capital, conduzidas pelo Estado, pelo mercado e pela própria subordinação do trabalho ao capital. Trata-se, portanto, de um processo educativo para a automediação, o autocontrole e auto-realização, através da liberdade substantiva e da solidariedade, onde os indivíduos sociais possam livremente reaprender o exercício ético, em acordo com suas reais necessidades.

Essa mudança paradigmática radical colocada como horizonte do processo educativo implica superar a separação entre governantes e governados, educadores, administradores e os que devem ser educados. Significa também interferir e estabelecer novas prioridades para o sistema produtivo, mediante a plena e livre deliberação dos indivíduos envolvidos, abolindo a dominância da lógica capitalista mercantil e seu poder de preterir as necessidades vitais em função do lucro, e estabelecer círculos viciosos de desperdício e escassez.

É dessa forma que educação e trabalho estão intimamente associados na reflexão sobre a mudança de paradigmas no sistema do capital e na forma histórica contemporânea do capitalismo globalizado. Para criar a sociedade de produtores livremente associados, capazes de uma intervenção consciente no processo histórico, é preciso um novo sistema de educação formal e não-formal.

Nesse sentido, Mészáros (2005) afirma que a educação continuada e a prática da autogestão da ordem social reprodutiva são inseparáveis. A educação para a autogestão significa habilitação dos indivíduos sociais para realizar o controle das funções vitais do processo metabólico social, que é um processo contínuo a exigir uma visão de totalidade sobre o sistema produtivo social, incompatível com uma educação vocacional estrita, e com uma ciência departamentalizada e fragmentada, que confina o indivíduo a funções utilitaristas, sem visão sobre a complexidade social e sem poder político para decidir sobre as questóes sociais.

A transição emancipadora de qualquer instituição educacional implica libertar os princípios da educação formal da imposição de conformidade à lógica do capital, e promover a transdisciplinaridade, no sentido da maior intensidade possível de troca com as práticas educacionais mais abrangentes que circulam no mundo vivido dos sujeitos coletivos.

Neste sentido ampliado, o papel da educação é romper com a internalização imposta pelas escolhas políticas do Estado controlado pelos interesses da lógica do capital. Trata-se de uma contra-internalização, ou contra-consciência, que busca antecipar uma visão geral, concreta e abrangente, de uma forma radicalmente diferente de gerir as funções globais de decisão da sociedade.

\section{A EMANCIPAÇÃO DA UNIVERSIDADE PÚBLICA}

É também nesse sentido que, considerando o momento histórico do capitalismo neo-liberal transnacionalizado, Santos (2005) propõe que, enquanto bem público, a universidade deve criar uma nova institucionalidade, promovendo o debate sobre um projeto de sociedade que fortaleça a globalização contra-hegemônica, ou seja, 
reciprocidade e benefício mútuo, fora dos regimes dominantes de comércio internacional. Nesse papel, a universidade deve conceber o projeto nacional de modo não isolacionista, dentro de uma lógica da globalização alternativa, que seja referência para definir interesses sociais prioritários de pesquisa.

Nessa mesma direção, Mészáros (2005) fala de um processo educativo que promova uma contraconsciência descolonizada, envolvendo a situação objetiva e a reação subjetiva dos indivíduos sociais, mediante um empreendimento crítico, uma filosofia de libertação, uma conscientização ativa e dinâmica.

Como poderíamos, então, pensar a transformação da instituição universitária e o papel social do conhecimento científico dentro dessa visão revolucionária da educação?

Em resposta à demanda pela recuperação da responsabilidade social da universidade, Santos propõe um conhecimento "pluriversitário", interativo e transdisciplinar, com inserção social, produzido em sistema aberto e a partir de relações sócio-políticas em rede, transformando, assim, o envolvimento preferencial da produção de conhecimento com os interesses do sistema do capital.

Porém, adverte o autor, a universidade pública só poderá ser o locus da produção desse novo tipo de conhecimento na medida em que for capaz de transformar a arrogância monopolista da razão tecnocrática totalitária numa razão democrática, com fronteiras abertas para a experiência do senso comum, fazendo desta um caminho de aprofundamento do caráter científico do conhecimento, ou seja, incorporando em seu modo de produção a experiência real de outras racionalidades, em contraponto à lógica capitalista.

Isto significa forjar um novo modelo de relações de produção de conhecimento no interior da instituição universitária, que possa superar a ética individualista e competitiva do mercado capitalista como modelo de relação social. Desconcentrar a propriedade dos meios de produção do conhecimento significa acesso democrático aos espaços acadêmicos, e formação técnico-científica que instrumentalize a participação dos novos protagonistas nas relaçôes de produção do conhecimento científico. Significa eliminar os obstáculos institucionais e ideológicos com que a universidade exclui os segmentos sociais interessados na mudança social, e promover a propriedade coletiva dos meios sociais de produção do conhecimento, num empreendimento onde todos sejam trabalhadores e criadores de um novo saber.

O salto epistemológico necessário nessa transição passa pela necessidade de superar a posição de confronto com que o paradigma positivista afirmou a legitimidade do discurso científico por oposição à noção de senso comum, sendo este visto enquanto ilusão, erro e distorção do real. Nesse sentido, dois aspectos devem ser considerados.

Primeiro, a própria noção de realidade que o paradigma cartesiano impôs de modo absoluto, ocultando o fato de que o real, ou a racionalidade pela qual definimos o que seja o real, é uma construção a partir dos diversos pontos de vista socioculturais que coexistem numa mesma sociedade, incluindo o ponto de vista da ciência. Dito de outra forma, nenhum sistema de conhecimento detém o privilégio da verdade sobre a definição do real. Verdades são decisōes éticas, antes de serem científicas. 
Advogando pela ruptura com a oposição entre ciência e senso comum, Santos (1989) adverte para que não se confie cegamente na razão científica, pois racionalidade e irracionalidade caminham sempre juntas na realidade humana.

Segundo, a incorporação do senso comum como condição para o salto epistemológico exigido pela transição paradigmática implica explicitar e superar as contradições básicas do sistema do capital, entre elas a dicotomia entre trabalho intelectual e prática social, entre ensino, pesquisa e extensão, no interior da instituição universitária.

Como demonstra Mészáros (2002), o capitalismo contemporâneo alcançou um grau historicamente inédito de subordinação das necessidades sociais às necessidades de auto-reprodução do capital. Quanto maior a competição, maior a destruição ou precarização da força humana de trabalho, e a degradação da relação metabólica entre os humanos, a tecnologia e a natureza.

Revalidar o senso comum no âmbito da construção acadêmica dos saberes técnico-científicos significa superar os efeitos perversos dessa lógica no interior das relações sociais de produção do conhecimento. Significa revolucionar, não simplesmente reformar, essas relaçôes, com uma atitude pedagógica na qual todos os sujeitos implicados devem reconhecer-se como aprendizes de um novo modo de apropriação coletiva dos meios sociais de produção do conhecimento.

Para Santos (1989, p. 37), o senso comum é "o menor denominador comum daquilo em que um grupo ou um povo coletivamente acredita", e, dependendo das condições sociopolíticas dominantes numa sociedade, ou instituição, se democrática ou autoritária, o senso comum tanto pode conter sentidos de resistência como de subordinação.

No sentido de uma experiência direta de mediação entre o humano e a natureza, o senso comum é uma visão de mundo enraizada no contexto do trabalho, ou seja, na atividade criadora não alienante, auto-realizadora e responsável dos indivíduos, e aí se apresentam qualidades extremamente favoráveis à construção de um novo paradigma e projeto de sociedade. Santos enumera algumas dessas qualidades: o senso comum é prático e pragmático, dá sentido e orientação para decisões; emerge das trajetórias e experiências de vida de um grupo social; produz confiança e segurança; é transparente e evidente, recusa a linguagem obscura e opaca; trabalha na horizontalidade das relações conscientes; é retórico e metafórico, se impõe pela persuasão.

O diálogo inter e transdisciplinar, a interlocução entre diversas áreas de conhecimento e com o conhecimento oriundo da prática social dos trabalhadores, é condição que se impóe para o enraizamento do conhecimento científico no mundo da vida e para a construção de um novo senso comum.

Trata-se do desafio de construir pontes entre o conhecimento popular que emerge do mundo vivido dos sujeitos coletivos e a prática da produção científica:

...a competência em saberes não científicos se enriquece enquanto tal no contato comunicativo e argumentativo com a competência em saber científico... a competência em saberes científicos se sabe enriquecer enquanto tal no contato comunicativo e argumentativo com a competência em saberes não científicos (SANTOS, 1999, p. 229). 
Coloca-se, assim, para a universidade pública, a tarefa de criar as condições institucionais da transição paradigmática para a emergência de uma ciência revolucionária, que possa responder à necessidade coletiva de formar indivíduos sociais aptos para o protagonismo da autogestão de um novo projeto de sociedade.

Essa missão da universidade pública aponta para uma diversidade de tarefas no curto prazo. Primeiro, para que a própria instituição e a comunidade universitária possam exercitar a superação da lógica do capital e gerar um novo projeto de sociedade, é preciso uma transição que aprofunde a mudança ética e de atitudes, da competição à colaboração solidária, unindo o trabalho intelectual à prática social. Novas relações de produção do conhecimento científico supõem a formação de novos sujeitos entre os produtores de conhecimento que já se encontram na universidade pública, professores, funcionários e estudantes, capazes de produzir o que Santos (1989, p. 41) denomina "um conhecimento pluriversitário solidário": unir trabalho e educação em um novo senso comum.

Para que isso aconteça, é preciso criar dentro da universidade estruturas e espaços curriculares democráticos, interdisciplinares e transdisciplinares, cuja dinâmica se enraíze em comunidades interpretativas que sejam espaços de acolhimento da diversidade de sujeitos sociais, tendo em vista a recriação das relações de poder e de produção de conhecimento.

Em terceiro lugar, para a eficácia teórica das formas de pensar, é preciso sistematizar propostas já existentes na sociedade e construir uma agenda de pesquisa visando garantir o rigor científico das novas teorias daí emergentes. Ao mesmo tempo, é preciso articular a atividade pensante à proposição de políticas públicas, reforçando a participação da universidade na gestão social.

Nesse sentido, é importante a parceria da universidade com programas de gestão pública e com instituições de formação vinculadas aos movimentos sociais. Isso permite que se abra na universidade um espaço de escuta das experiências e reflexões desses movimentos.

Enquanto espaço privilegiado do diálogo e da disputa por novos sentidos na construção de um projeto de sociedade, por ser pública e democrática, a universidade deve desenvolver competência institucional para sustentar processos de luta por uma nova correlação de forças entre interesses diferenciados na produção do conhecimento científico.

A articulação institucional e teórica necessária para uma transformação paradigmática de tal ordem deve pautar-se pelo compromisso com as questôes relacionadas à formação dos sujeitos e às demandas dos movimentos sociais, e pela visão da diversidade regional, em suas propostas pedagógicas e projetos de pesquisa.

A educação no mundo da vida que a luta de classes proporciona aos sujeitos oriundos dos movimentos sociais das classes subalternas pode contribuir para internalizar na universidade os valores da solidariedade e da democracia direta, como base para um novo modo de organização das relaçóes acadêmicas.

Dessa forma, há uma convocação à construção coletiva de novas práticas sociais solidárias no interior da instituição universitária, o que certamente não exclui conflitos e disputas por hegemonia, porém rompendo com a competitividade brutalizada 
da política capitalista, pois a verdadeira relação democrática é aquela que permite lidar com esses conflitos de modo solidário em função do reconhecimento de necessidades e interesses coletivos. A solidariedade se coloca como opção consciente por um novo modo de produção que exige um novo aprendizado, onde a prática é inspiradora de novas possibilidades, a partir da relação orgânica com as necessidades colocadas na luta social.

Trata-se, portanto, para a universidade pública, de um momento de profunda transição no seu processo de existência histórica e na luta dos movimentos sociais pela ocupação do seu legítimo lugar no processo de produção do conhecimento científico.

Entre a ciência e a vida, a crise e a transição trazem a transgressão, o conflito, a resistência e o profundo encontro interpretativo entre ética e política, a imaginação criadora e a racionalidade do pensamento, na luta da inteligência pela emergência de um novo projeto de sociedade.

\section{Referências}

MÉSZÁROS, István. Para além do capital. São Paulo: Boitempo, 2002. . A educação para além do capital. São Paulo: Boitempo, 2005.

MORIN, Edgar. O Método. Vol. IV - As idéias: a sua natureza, vida, habitat e organização. Lisboa: Publicações Europa-América, 1992.

SANTOS, Boaventura de Sousa. Da idéia de universidade à universidade de idéias (1989), In: Pela mão de Alice. O social e o político na pós-modernidade. São Paulo: Cortez, 1999. p. 187-234.

. Ciência e senso comum. In: . Introdução a uma ciência pós-moderna. Rio de

Janeiro: Graal, 1989. p. 31-45.

. A Universidade no século XXI. Para uma reforma democrática e emancipatória da

Universidade. São Paulo: Cortez, 2005. 


\section{Science and society: education in times of paradigmatic frontiers}

\section{Abstract}

This study bridges the ideas of Boaventura de Sousa Santos with regards to the role of the public university in the construction of a project for a society, one that is counter-hegemonic to capitalist globalization and those of István Mészáros dealing with the radicality of education beyond capital. To bring together those two views of social change, the vision of Edgar Morin on the complex nature of paradigms and the social and cultural conditions for their transformation was used. The article inquires about the possibilities of production of a new knowledge rooted in the social struggles for the overthrow of the hegemony of the logic of capital and its determination over material, cultural and educational production in our society. The public university is considered a privileged space for democratizing the production of scientific knowledge and contributing to the construction of a revolutionary project of society.

Keywords: Public University. Paradigmatic change. Scientific knowledge.

\section{Science et société: l'éducation à l'époque des frontières paradigmatiques}

\section{Résumé}

Cette étude fait le pont entre les idées de Boaventura de Sousa Santos au sujet du rôle de l'université publique dans la construction d'un projet de société qui soit contre-hégémonique à la globalisation capitaliste et celles de István Mészáros qui traitent de la radicalité de l'éducation au delà du capital. Pour rapprocher ces idées sur le changement social, la vision d'Edgar Morin sur la nature complexe des paradigmes et les conditions sociales et culturelles pour leur transformation a été utilisée. L'étude pose la question sur les possibilités de la production d'un nouveau savoir enraciné dans les luttes pour la suppléance de l'hégémonie de la logique du capital et sa détermination sur la production matérielle, culturelle et éducationnelle dans notre société. L'université publique est considérée un espace privilégié pour la démocratisation de la production du savoir scientifique et la construction d'un projet révolutionnaire de société.

Mots clefs: Université publique. Changement paradigmatique. Savoir scientifique.

\section{Ciencia y sociedad: la educación en tiempos de fronteras paradigmáticas} Resumen

Este artículo hace un puente entre las ideas de Boaventura de Sousa Santos con respecto del papel de la universidad pública en la construcción de un proyecto de sociedad contrahegemónico a la globalización capitalista, y las ideas de István Mészáros, a respecto de la radicalidad de una educación para más allá del capital. En la costura de estas dos visiones del cambio social, utilizamos la visión de Edgar Morin sobre la naturaleza compleja de los paradigmas y las condiciones socioculturales de su transformación. Se indagan aqui las posibilidades de producción de un nuevo conocimiento enraizado en las luchas sociales por la superación de la hegemonía de la lógica del capital y de su determinación sobre la producción material, cultural y educacional de nuestra sociedad. La universidad pública es considerada un espacio privilegiado de democratización de la producción del saber cientifico y de contribución a la construcción de un proyecto de sociedad revolucionario.

Palabras-clave: Universidad pública. Cambio de paradigmas. Saber científico.

Recebido: 03.07.2006

Aceito: 02.04.2007 